\title{
Incorporating resilience and cost in ecological restoration strategies at landscape scale
}

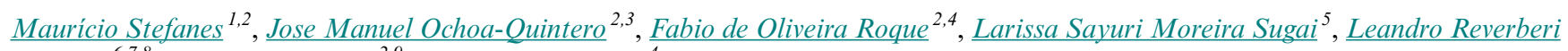 \\ $\underline{\text { Tambosi }}^{6,7,8}, \underline{\text { Reinaldo Lourival }}^{2,9}$ and $\underline{\text { Susan Laurance }}^{4}$
}

\begin{abstract}
The restoration of deforested or degraded areas can contribute to biodiversity conservation and global resilience given the current and projected impacts of climate change. In recent years, a robust array of ecological restoration frameworks have been generated to address restoration challenges at large scales in different ecosystems around the world. Unfortunately, the costs associated with restoration at such scales greatly challenges the implementation of such frameworks. We used landscape ecology principles with multicriteria optimization of landscape resilience and agricultural productivity as a way to mitigate the trade-offs between production and restoration. We used the Cerrado biome in Mato Grosso do Sul State, Brazil, as a case study to apply our framework. We compared three scenarios: minimal legal compliance (MLC); selection by ecological resilience (SER); and selection by restoration cost (SRC). Our results show that increasing the restoration target from MLC (25\%) to SER (30\%) means moving from 968,316 to 1592 million hectares, which can represent a huge opportunity cost for agricultural lands. However, because costs and resilience are not homogeneously distributed throughout landscapes, we can select areas of intermediate ecological resilience and low cost, for the same restoration area target. This process can reduce potential conflicts and make restoration a more viable process. Our results also reveal some areas that can be particularly important for reconciling agriculture and landscape restoration. Those areas combined high and intermediate resilience and an above average profitability. This could mean that increasing restoration in this area could be very expensive, assuming that our proxy roughly represents the restoration implementation cost. However, there is another important message here, that some areas can be productive at the same time that they maintain levels of resilience above the legal compliance, which facilitates win-win scenarios in human-dominated landscapes.
\end{abstract}

Key Words: decision-making tool; ecological resilience; fragmentation; opportunity cost; prioritization restoration; restoration costs; trade-off analysis

\section{INTRODUCTION}

Landscape conversion is the main cause of natural habitat loss across the world. Recent estimates show that $70 \%$ of the grassland, $50 \%$ of the savanna, $45 \%$ of the temperate deciduous forest, and $27 \%$ of the tropical forest biome have already been cleared or converted into agricultural lands (Foley et al. 2011). The ecological restoration of deforested or degraded areas can contribute enormously to biodiversity conservation and global stability and resilience, given the current and projected impacts of climate change (Steffen et al. 2015). Moreover, tropical regions have the largest need for restoration efforts, almost twice the area required in temperate regions (Minnemeyer et al. 2011).

In the past decades, restoration actions were decided in terms of urgency or specific demands at local scales, called the "gardening approach" (Metzger and Brancalion 2013). Currently, landscape ecology frameworks have emerged to guide decisions at large scales, including important aspects of habitat connectivity and ecosystem functionality (e.g., Jackson and Hobbs 2009, Metzger and Brancalion 2013). In a recent global meta-analysis on the ecological drivers of forest restoration success, Crouzeilles et al.
(2015) concluded that landscape restoration success is context dependent, but in general, it is influenced by the level of landscape connectivity and historic disturbance. Although there have been significant advances in increasing ecological resilience at a large scale, landscape restoration projects rarely incorporate socioeconomic dimensions despite aspects such as governance, social-political, and financial constraints being key determinants of restoration success (Aronson et al. 1993, Rodrigues et al. 2009, Nilsson and Aradóttir 2013). Thus, there is an urgent need to include the socioeconomic dimension in large-scale restoration initiatives.

Minimizing the impact of economic and political constraints in conservation actions through trade-off analytical frameworks allows us to explore scenarios to achieve particular objectives without undermining others (Moffett and Sarkar 2006, Loyola et al. 2009). The number of studies and initiatives that incorporate economic and political constraints in prioritizing areas for biodiversity conservation is increasing in recent years, largely driven by advances in systematic planning approaches (Margules and Pressey 2000, Noss et al. 2009) and demands from

${ }^{1}$ Faculdade de Ciências Biológicas e Ambientais - FCBA/UFGD - Brazil, ${ }^{2}$ Programa de Pós-Graduação em Ecologia e Conservação, Campo Grande - MS/Brazil, ${ }^{3}$ Corporación para Investigaciones Biológicas, Medellín, Colombia, ${ }^{4}$ Centre for Tropical Environmental and Sustainability Science, College of Science and Engineering, James Cook University, Cairns, Australia, ${ }^{5}$ Instituto de Biociências, UNESP - Univ Estadual Paulista, Rio Claro, Departamento de Ecologia, Programa de Pós-Graduação em Ecologia \& Biodiversidade, São Paulo, Brazil, ${ }^{6}$ Departamento de Ecologia, Universidade de São Paulo, São Paulo, Brazil, ${ }^{7}$ Centro de Engenharia, Modelagem e Ciências Sociais Aplicadas, Universidade Federal do ABC, Santo André, Brazil, ${ }^{8}$ Ecology, Evolution and Environmental Biology, Columbia University, New York, USA, ${ }^{9}$ Nature and Culture International, Del Mar, California, USA 
international agreements, e.g., Global Partnership on Forest/ Landscape Restoration, Convention on Biological Diversity, Bonn Challenge, http://www.bonnchallenge.org/). Nonetheless, there are also large gaps in data availability that must be overcome (Joppa et al. 2016). These initiatives use different proxies for conservation costs and in general the studies on spatial prioritization are moving from ignoring to recognizing spatial heterogeneity, including multiple costs like land acquisition and management (Armsworth 2014). The best way for including costs in conservation planning is context dependent. So, in circumstances where detailed information about monetary costs are largely unavailable, e.g., for large-scale landscape modeling, the use of proxies, such as human population density or gross productivity value per capita, or potential gross revenue of agriculture (per hectare), can provide a starting point. This approach is not only for addressing the cost of land acquisition and management, but also for political and social constraints. From a restoration perspective, although researchers are aware of the importance of considering restoration costs, few studies have explicitly included cost layers (e.g., Crossman and Bryan 2006, Brancalion et al. 2012, Crouzeilles et al. 2015, Iftekhar et al. 2016), which makes most initiatives very limited in terms of their implementation.

In this study, we present a user-friendly framework to facilitate the dialogues among decision makers, landowners, and other stakeholders by visualizing trade-offs among restoration deficit, environmental resilience, and costs in the selection of areas for restoration. Our aim is to provide a framework that could be applied in different contexts and even when there is insufficient information on biodiversity patterns and an estimated restoration cost. Using the Brazilian savanna as a case study, we assess three restoration scenarios based on different restoration targets: (i) minimum legal compliance (MLC) ensures that native vegetation covers $25 \%$ of the landscape according to the Brazilian Forest Code (FC; Government of Brazil 2012); (ii) selection by ecological resilience scenario (SER) is based on native vegetation covering $30 \%$ of the landscape corresponding to environmental resilience; and (iii) selection by restoration cost scenario (SRC) is also based on native vegetation also covering $30 \%$ of the landscape while considering restoration costs.

Although compliance is preferable at the property level by federal and state laws, landowners are allowed to offset their legal requirements by protecting or restoring habitats on other properties within the same biome. In this context, there is a legal precedent for using landscape approaches in restoration planning, which have also been demonstrated to provide better cost-effective conservation strategies when compared with those designed based on individual properties (Kennedy et al. 2016).

In our SRC scenario, we incorporated the human dimension by assuming that the average productivity per hectare multiplied by the vegetation deficit for restoration represents a proxy for social, economic, and political costs. We believe that this proxy is a practical and valuable way to include the degree to which socioeconomic and political difficulties influence implementation of ecological restoration actions at the large scale. By incorporating restoration costs, we aim to underpin decision making in countries where political power is dispersed, subject to economic lobbies (e.g., negotiation of the Forest Code in Brazil, discussed in Soares-Filho et al. 2014), and vary according to stakeholder interests. Our framework exemplifies a way to reduce costs of restoration while maximizing effective biodiversity gains by using ecological resilience concepts at the landscape scale (Aronson et al. 1993, Tambosi et al. 2014).

\section{The case study area}

We exemplify the proposed framework using the Cerrado biome within Mato Grosso do Sul state in Brazil, a region characterized by dramatic recent conflicts between indigenous people, agribusiness, and conservationists (Sullivan 2013). The Cerrado biome is a global hotspot of biodiversity (Myers et al. 2000), and supports a mosaic of open and forested vegetation formations that cover $23 \%$ of the Brazilian territory.

The Cerrado encompasses 216,086 $\mathrm{km}^{2}$ in Mato Grosso do Sul state, along with two other biomes: the Pantanal wetland in the west and the Atlantic forest in the east (Fig. 1). Despite its size only $32 \%$ of its original extent remains (IMASUL 2015). Landuse changes in Cerrado are mainly related to conversions for highly profitable crops such as corn, soybean, cotton, beans, sugarcane, and eucalyptus plantations (INPE/Canasat 2015, Overbeck et al 2015). The high-level of native vegetation conversion is not only affecting the biodiversity within this biome, but may also compromise the functioning of neighborhood systems such as the Pantanal wetlands (Roque et al. 2016).

\section{Legal framework}

In Brazil, all states are components of the National Environmental System (Government of Brazil 1981), the federal level that defines minimum mandatory land allocation for biodiversity protection. The most important piece of legislation influencing restoration activities is the recently modified Forest Code-FC/2012 (Government of Brazil 2012; for a comprehensive view about the Forest Code, see Soares-Filho et al. 2014 and Brancalion et al. 2016). According to the FC/2012, rural properties within the Cerrado need to set aside at least $20 \%$ of the area for biodiversity maintenance in the form of legal reserves (LR). In cases of noncompliance, private landowners are required to either recover the native vegetation within their properties or to set aside lands as LR elsewhere within the same biome and preferably in the same state (Soares-Filho et al. 2014). Furthermore, private properties also need to keep native vegetation in permanent protection areas (PPA) that are regions along streams, rivers, hilltops, and on steep slopes $\left(>45^{\circ}\right.$, details are in $\mathrm{FC} / 2012$ ).

Although the review of the FC has been controversial (SoaresFilho et al. 2014), this legislation allows us to quantify the deficit of mandatory native vegetation cover and facilitate the offsetting through restoration, but only of the LR areas. If the FC/2012 law is accurately applied, the sum of all remaining native vegetation (LR and PPAs) should be nearly $25 \%$ of the Cerrado's landscape (Kennedy et al. 2016) excluding public lands, urban areas, and water surface. Combining the existing protected areas, indigenous reserves with the LR and PPAs from private lands would considerably increase the benefits of ecosystem services and biodiversity protection. We used these mandatory percentages as references to build and compare possible scenarios in our study. 
Fig. 1. The study area is located in the Cerrado biome in Mato Grosso do Sul state, Brazil, comprising $61 \%$ of the state area. It is located in the central axis adjoining the Pantanal wetland and the Atlantic Forest.

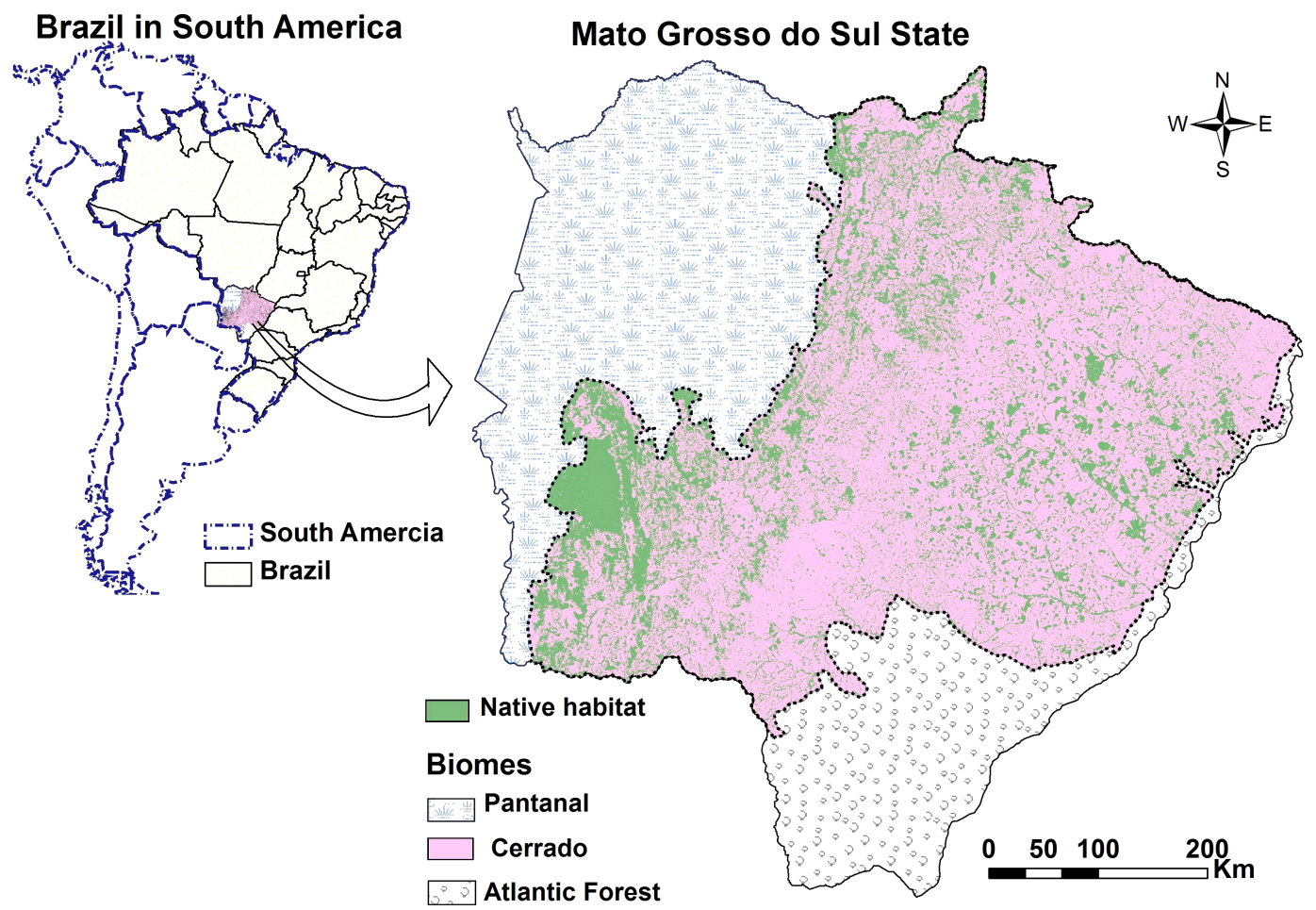

\section{Framework presentation}

The proposed framework consists of three main steps (Fig. 2): (1) primary information compilation: (i) definition and division of the study area into planning units (PU) and, (ii) estimating native vegetation and anthropogenic areas within PUs; (2) setting restoration targets: (i) calculating ecological resilience, (ii) computing deficit of native vegetation, and (iii) calculating agricultural productivity per PU; and (3) trade-off analysis of scenarios: minimal legal compliance (MLC), selection by ecological resilience (SER), and selection by restoration cost (SRC). Finally, we define a priority ranking for ecological restoration based on the higher ecological resilience and lowest restoration cost, and estimated the proportion of $\mathrm{PU}$ in each scenario overlapping with PU with higher priority according to the estimated ranking.

\section{Step 1: Primary information}

\section{Planning units (PUs)}

The use of PUs is an important step to define comparable units of analysis and to calculate the landscape metrics. Given the extent of the studied area, we defined the PU as hexagons of 10,000 ha. Landscape metrics based on similar sized planning units have been successfully used as biodiversity surrogates in other conservation studies (Lourival et al. 2009, Banks-Leite et al. 2011, Ochoa-Quintero et al. 2015).

Estimating native vegetation and anthropogenic areas We obtained a land use and vegetation cover map of the Mato
Grosso do Sul state from 2007, provided by the state government (IMASUL 2015). Currently, this is the most comprehensive mapping of the state available. It contains 52 classes, whereby 34 are native vegetation types and landforms and 18 are land use classes. Because the legal framework of the FC/2012 does not consider typological differences within the Cerrado biome, we opted to group all native vegetation classes in one class, hereafter called habitat, and named remaining land use classes, i.e., agriculture, sugar cane, livestock farming, silviculture, and urban areas, as anthropogenic area.

\section{Step 2: Setting targets to ecological restoration}

Native vegetation cover and landscape connectivity: PC index To estimate landscape connectivity, we used the "probability of connectivity" index (PC index) that defines the degree of habitat connectivity within a landscape based on graph theory, which accounts for both habitat amount and configuration, and species dispersal ability (Pascual-Hortal and Saura 2006). The PC index is based on a probabilistic model of a negative exponential function that considers $50 \%$ probability of crossing a $100-\mathrm{m}$ gap between two native vegetation patches. Therefore, habitat pairs with distance tending to zero present higher connection probability. This criterion was adopted to represent an average value $(100 \mathrm{~m})$ of the dispersal ability of 84 target species for conservation selected by regional biodiversity experts in the state (Sugai et al. 2014). Values of the PC index vary from 0 (zero), when there is no native vegetation in the PU, to 1 (one), when the entire PU is occupied by native vegetation. All analyses were 
Fig. 2. Steps of the methodological framework: (1) primary information compilation: (i) partition of study area into planning units (PUs), and (ii) quantification of anthropogenic and habitat areas from land use and land cover maps; (2) setting targets for the scenarios and calculation of ecological resilience and restoration cost; (3) scenario trade-off analysis, priority ranking, and overlapping between PUs from different scenario and high priority PU.

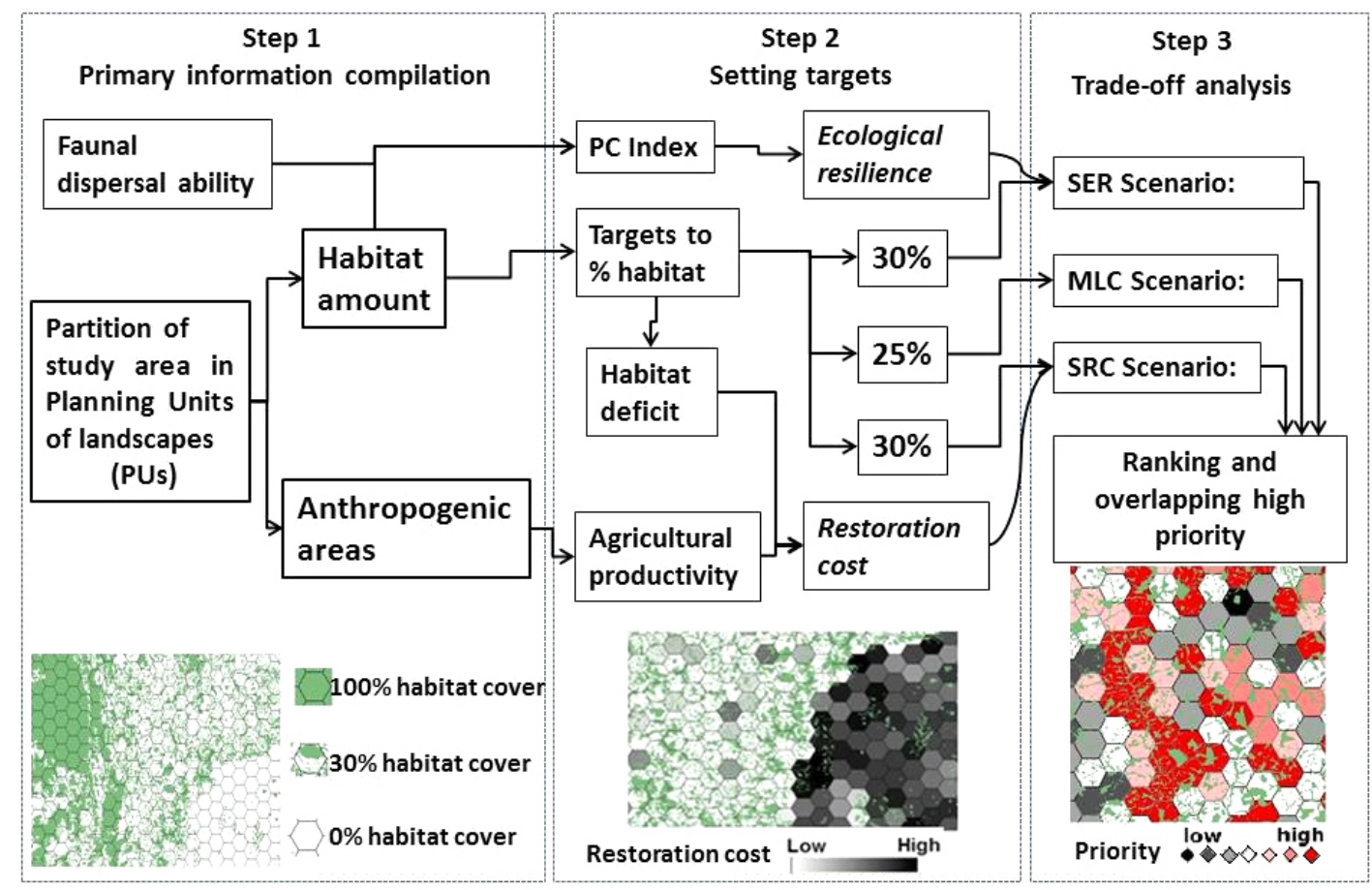

conducted in the software Conefor Sensionode - CS22 (PascualHortal and Saura 2006).

\section{Estimating ecological resilience}

Although the measurement of ecological resilience at the landscape scale is a complex issue (Rodrigues et al. 2009, Pardini et al. 2010, Tambosi et al. 2014), we recognize two important features for its measurement: (1) functional connectivity and (2) habitat amount. We used the relationship between habitat remnant and connectivity given by the PC index to categorize PUs into classes of resilience: low, intermediate, and high (Fig. 3). We generated a resilience range considering the relationship between PC index and the amount of habitat in the landscape. Those, PUs with less than $20 \%$ of remaining vegetation were considered in the low resilience category, mainly because they often require high investment and lower recovery prospect of success, and consequent low restoration priority rank (Tambosi et al. 2014). We categorized PU as high resilience according to these criteria: (i) if they presented more than $60 \%$ of remaining vegetation, or (ii) if they presented between $40 \%$ and $60 \%$ of remaining vegetation and $\mathrm{PC}$ index above the median value for this range (Tambosi et al. 2014). These PUs were also categorized as low priority for restoration because they are expected to keep most of their original biodiversity given the greater area of remaining vegetation (Pardini et al. 2010, Phalan et al. 2011). Finally, those PUs ranging from $20 \%$ to $40 \%$ of native vegetation and that are not included in the high resilience category are considered as intermediate resilience. These PUs were considered priority for
Fig. 3. Distribution of the 2353 planning units (PUs) according to the habitat amount and landscape connectivity (PC index). Any PUs with less than $20 \%$ of habitat cover were considered low resilient (red). PUs with high resilience were those with more than $60 \%$ or among $40 \%$ and $60 \%$ habitat cover with PC index value above average $\mathrm{PC}$ index value for this habitat cover interval (green). PUs with intermediate resilience were those between $20 \%$ and $40 \%$ or less than $60 \%$ habitat cover and below average PC index (yellow).

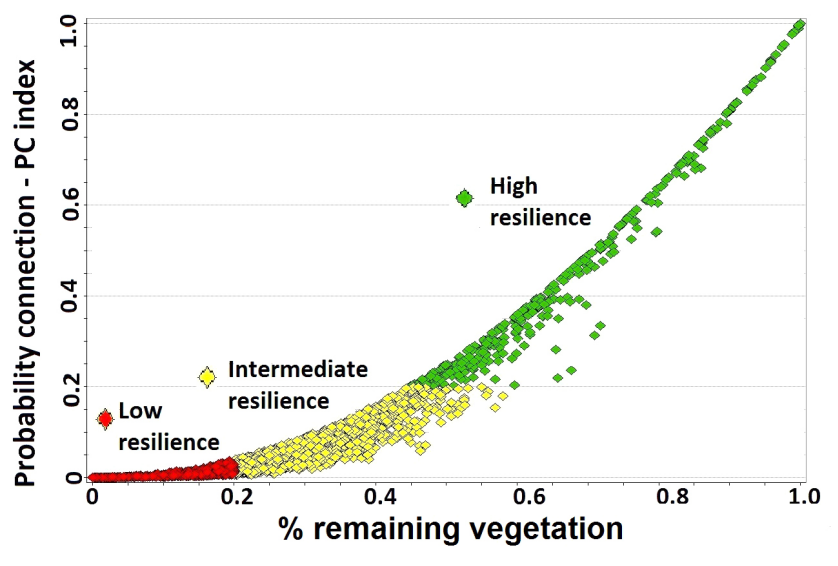


restoration actions because at intermediate resilience levels, the effects of habitat loss on species extinction are minimized, and the habitat amount held can provide good chances of recolonization (Tambosi et al. 2014). This approach allowed us to handle resilience fluctuations in two simultaneously ways: the categorical (low, intermediate, and high) and the continuous resilience index ( 0 to 1$)$. We extracted this continuous resilience from average of the functional connectivity and habitat amount. As result, the intermediate category is represented by intervals 0.10 to 0.37 in the resilience range, whereas low resilience coincides with values $<0.10$ and high resilience by values $>0.37$.

\section{Quantitative targets}

We set two habitat percentage values as ecological restoration targets. In the first target, we adopted $25 \%$ of habitat in each PU based on the Forest Code target, which states that properties in the Cerrado biome should have at least $25 \%$ of native vegetation, owing to $20 \%$ for LR plus $5 \%$ estimated for riparian forest (Kennedy et al. 2016). In the second target, we considered $30 \%$ of habitat inside PU as a minimum value to maintain biodiversity based on reports of dramatic decline in species richness when remaining vegetation cover goes below this proportion (Pardini et al. 2010, Banks-Leite et al. 2014, Rodrigues et al. 2016). Once the ecological restoration targets were established, we calculated the habitat deficit to achieve both targets in each PU.

\section{Agricultural productivity}

To estimate the agricultural productivity within PU, we used the average gross productivity value (GPV) of different agriculture activities (livestock, silviculture, and sugar cane farming) for Mato Grosso do Sul state in 2013. The estimated revenue of GPV on these land uses is provided by the Brazilian Minister of Agriculture, Livestock and Supply according to gross sales within the property in Brazilian Real (R\$/ha). We multiplied the area of each agricultural activity inside the PU by its GPV, and summed the products to result in the total agricultural productivity. We assessed the GPV from the abovementioned anthropogenic classes because they were proportionally predominant in the state (IMASUL 2015).

\section{Estimating restoration cost}

Here we use the term "restoration cost" derived from "opportunity cost," which defines the cost of an alternative that must be forgone to pursue a given action (Buchanan 1991). We parallel this concept from theoretical microeconomics in consideration of the Forest Code, where landowners that maintain remaining native vegetation on their properties have an opportunity cost related to this area. On the other hand, if the remaining vegetation is converted into arable land, there will no longer be an associated opportunity cost. We assumed that the total agricultural productivity is a reasonable estimate of the PU average profitability. In this sense, any habitat deficit for legal compliance or other established target for ecological restoration, such as the targets proposed in this framework, has an associated value of restoration cost. We proposed an index that combines the habitat deficit and the agricultural productivity within each PU as a proxy of the socioeconomic difficulty to implement ecological restoration actions at the landscape scale. The greater the vegetation deficit and the greater agricultural productivity will tend to have a higher restoration cost. We acknowledge that landowners vary in their willingness for restoration, especially when dealing with large areas needed for restoration. We presumed that the overall logic is to maximize profit and minimize costs, and that the common sense among landowners is that restoration action is a cost rather than an investment. Thus, the agricultural productivity can be a good weighting factor for restoration strategies, without sinking into the "worthless land hypothesis," where only poor lands are allocated to conservation (Hall 1988).

We calculated the restoration cost by multiplying each PU's agricultural productivity $(\mathrm{R} \$$ ) by the area of habitat deficit for the same PU. Thus, the greater vegetation deficit, the larger the restoration cost $(\mathrm{R} \$ / \mathrm{PU})$. If there is no deficit in a PU for a certain target, even high productivity will return zero restoration costs. We used Boolean logic to calculate the restoration cost (Equation 1). Note that it only makes sense to calculate the restoration cost for landscapes with habitat deficit according to the established targets.

$$
R C=A P * H D
$$

Where:

$R C=$ Restoration cost;

$A P=$ Agricultural productivity

$H D=$ Habitat area deficit

In addition, when productivity in a PU is zero because they are located in protected areas or contain water bodies, we also set zero as the restoration cost.

\section{Step 3: Trade-off analysis of scenarios}

We addressed three scenarios to analyze the trade-offs between agricultural productivity and restoration cost to identify possible ways to implement ecological restoration actions in the study area.

1. Minimal legal compliance scenario (MLC): We adopted a target of $25 \%$ habitat coverage within each PU. Thus, PUs below this value have area deficits and should be restored in the same PU to overcome the vegetation deficit.

2. Selection by ecological resilience scenario (SER): We considered a target of $30 \%$ of habitat coverage within each PU as a minimum habitat amount to safely maintain biodiversity beyond possible abrupt declines. We used the landscape resilience criteria proposed by Tambosi et al. (2014), and focused the analysis only in PU with intermediate resilience.

3. Selection by restoration cost scenario (SRC): We also considered a target of $30 \%$ of habitat inside each PU, and selected only the PU with restoration cost below the average of restoration costs of all PUs. We set this value as cut-off to selecting the smaller restoration cost

\section{Ranking priorities}

We explored the trade-off between ecological resilience and restoration cost proposing a priority ranking for ecological restoration. We ranked as priority the PU with the highest ecological resilience and the lowest restoration cost. Because an increase in one variable leads to a decrease in the other because both variables are derived from the amount of area, we ranked the PU with habitat deficit by subtracting the restoration cost from the ecological resilience (Equation 2). 
Fig. 4. Selected planning unit (PU) for different targets for ecological restoration in the Cerrado biome of the Mato Grosso do Sul state, and respective relationships between landscape resilience and restoration cost. (a) Minimal legal compliance scenario (MLC), (b) selection by ecological resilience scenario (SER), and (c) selection by restoration cost scenario (SRC).
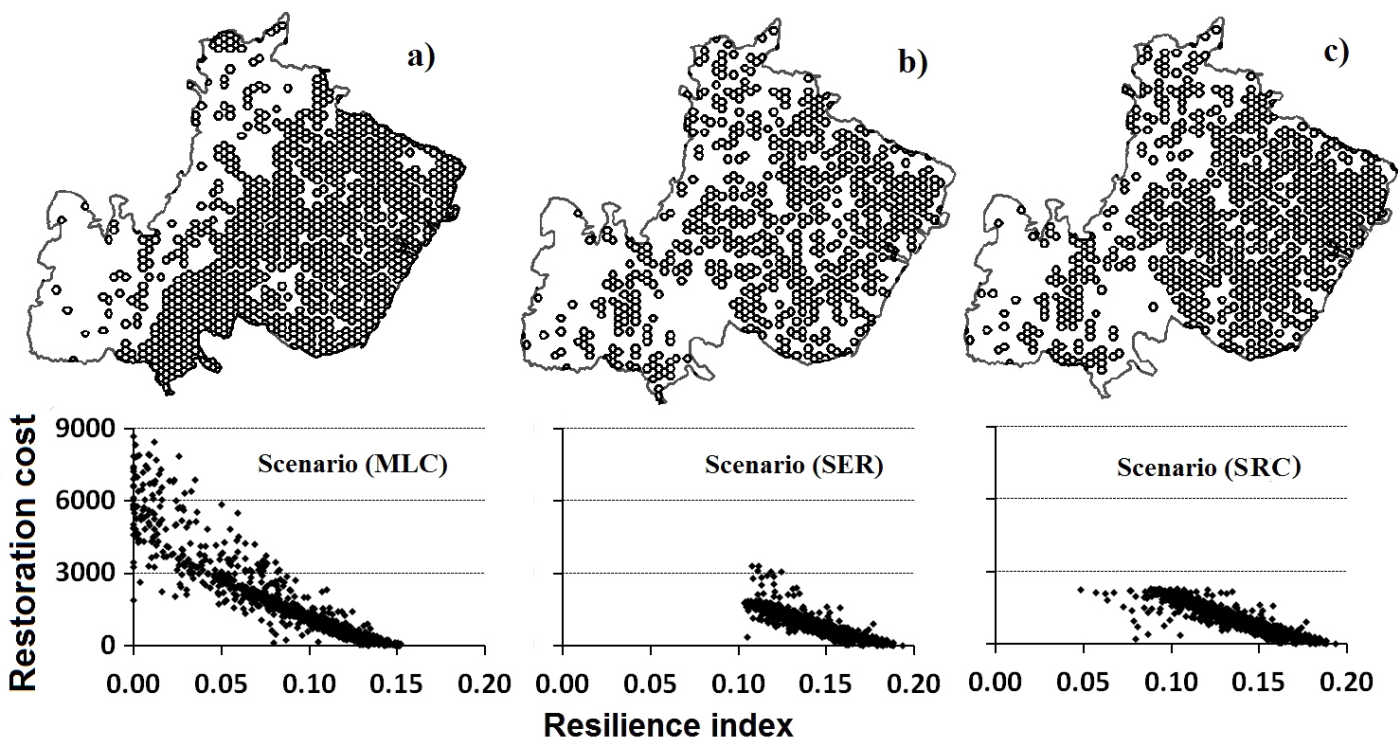

$$
P=E R-R C
$$

Where:

$$
\begin{aligned}
& P=\text { Priority Rank } \\
& E R=\text { Ecological Resilience } \\
& R C=\text { Restoration Cost }
\end{aligned}
$$

Thus, higher rank position was attributed to PUs that have lower productivity and higher landscape resilience. We finally compared each scenario performance, based on the PUs overlapping with higher priority obtained from the ranking.

\section{RESULTS}

\section{Scenario outcomes}

In the visual exploration of the trade-off analysis (Fig. 4), we outlined the tendency of lower restoration cost in PUs with higher landscape resilience. Moving from the MLC to the SRC scenarios, there is a decrease of selected PU, but accordingly, an increase of selected PU with intermediate resilience.

In the minimal legal compliance scenario (MLC), almost half of the PUs (1108 of 2353 PUs) were below the $25 \%$ habitat target and required restoration action totaling 968.300 hectares (Fig. 5). In the selection by ecological resilience scenario (SER), from the 1423 PUs $(1,592,345 \mathrm{ha})$ with habitat deficit to reach the $30 \%$ habitat target, 680 PUs presented intermediate landscape resilience (Fig. 4b), corresponding to 354,277 hectares to be restored (Fig. 5). Finally, in the selection by restoration cost scenario (SRC), from the 1423 PUs below the 30\% habitat target, 875 were below the average restoration cost, and most of them (667) had intermediate resilience. Following the SRC scenario 577,528 hectares needs to be restored (Fig. 5).
Fig. 5. In this bidimensional graph we examine the variables: restored area (hectares; $\mathrm{x}$-axis), the percentage of planning units (PUs) to be restored and the accumulated cost of three scenarios (Brazilian Currency Real). The left y-axis (solid line) shows the percentage of PUs to be restored as will fulfill the target (restored hectares). The y-axis on the right (dotted line) shows the accumulated restoration cost for the amount of hectares restored by the model.

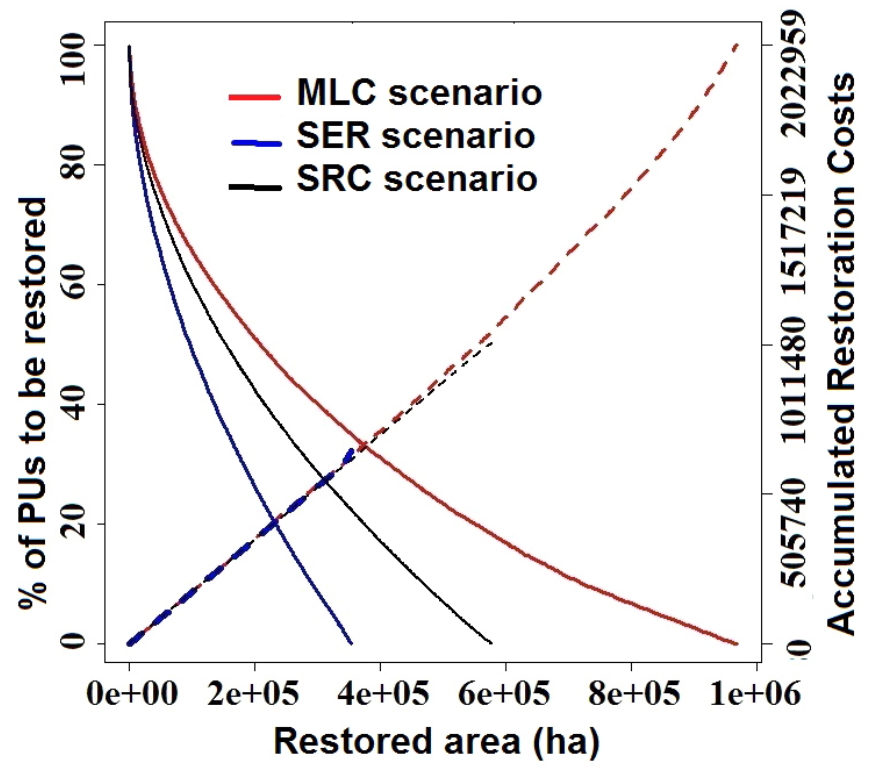


Considering the accumulated restoration cost of each scenario, MLC presented by far the highest accumulated restoration cost per unit area Brazilian Real $\left(2.02 \times 10^{6}\right)$, followed by SRC $(1.01$ x $\left.10^{6}\right)$, and SER $\left(6.53 \times 10^{5}\right.$; Fig.5, Table 1). Although SRC represented a higher accumulated cost than SER, the restoration cost decreased from 1.84 in SER to 1.76 in SRC. As expected, increasing the restored area will result in higher accumulated costs, as evidenced by modeling the interactions among three main parameters: restored area, \% of PUs restored, and accumulated costs; nonetheless our results showed that same accumulated cost and \% of PUs (e.g., 505,740 vs 35\%) lead to different outputs in terms of total restored area, with clear gains in the scenario SRC (Fig. 5).

Table 1. Scenarios, number of planning units (PUs), cost per hectare, and percentage of overlapping with high priority according to the ranking process. MLC $=$ minimal legal compliance scenario; SER = selection by ecological resilience scenario; and $\mathrm{SRC}=$ selection by restoration cost scenario.

\begin{tabular}{|c|c|c|c|c|c|}
\hline & \multicolumn{4}{|c|}{ Scenarios summaries } & \multirow{2}{*}{$\begin{array}{c}\text { Ranking priority } \\
\text { comparative } \\
\% \text { High priority } \\
\text { overlapping }\end{array}$} \\
\hline & $\begin{array}{c}\text { Selected } \\
\mathrm{PU}\end{array}$ & Total cost & $\begin{array}{c}\text { Cost } \\
\text { hectare }\end{array}$ & $\begin{array}{c}\text { Total } \\
\text { area (ha) }\end{array}$ & \\
\hline $\begin{array}{l}\text { M- } \\
\text { LC }\end{array}$ & 1108 & $2.02 * 10-6$ & 2.08 & 968,316 & 47.09 \\
\hline SER & 680 & $6.53 * 10-5$ & 1.84 & 354,277 & 47.79 \\
\hline SRC & 875 & $1.01 * 10-6$ & 1.76 & 577,528 & 61.49 \\
\hline
\end{tabular}

\section{Trade-off analysis and ranking priority areas for restoration}

In total, 875 PUs were identified as a high priority for restoration, with values that are $<2271$ average restoration cost and more than 0.08 resilience according to the $30 \%$ restoration target (Fig. 6). From this set of high priority PUs, the MLC and SER scenarios presented the lower overlapping proportion $(47.09 \%$ and $47.79 \%$, respectively), while the SRC scenario got the largest one $(61.49 \%$; Table 1). It is important to note that by ranking the priority areas for ecological restoration based on an ecological resilience weighed by restoration cost, landscapes with intermediate resilience and high restoration cost are dropped to a lower priority position for restoration (Fig. 6).

\section{DISCUSSION}

Setting restoration priorities is a controversial issue. Despite costeffectiveness, degraded areas are prioritized because they need urgent actions (Aronson et al. 1993, Lamb et al. 2005). Alternatively, researchers suggest prioritizing intermediate degraded areas because the outcomes in terms of costs and benefits are higher, particularly when there are expected gains from increasing environmental resilience (Tambosi et al. 2014). We believe that both views should guide decisions, but in different contexts. Our framework, based on trade-off analysis between ecological restoration demands and restoration costs of setting aside agricultural lands, provides a spatially explicit tool for setting restoration targets and priorities under different scenarios.

As a data visualization tool, our framework allows decision makers to visualize important landscape trends and patterns while considering current challenges. For example, if the aim of a restoration program is focused on recovering more degraded areas, restoration targets can be easily depicted from our minimum legal compliance scenario. This scenario shows the deficits on native vegetation cover per landscape even if encountering high costs. In this perspective, restoration should be focused on matching local needs and law compliance. So, a specific planning unit may have lower restoration priority in the general context, but, it may have a high demand for local restoration (Benayas et al. 2009) because of the following: reducing environmental impacts in degraded areas, improving environmental services, recovering area of native vegetation along rivers, or increasing habitat for declining species, that cannot be compensated in alternative places.

Moving forward, a restoration program could decide for a more ambitious objective by setting restoration targets beyond regulatory compliance. In this regard (exemplified by SER and SRC scenario), restoration faces similar challenges as those of prioritizing conservation areas using systematic processes of planning, because in any decision there are gains and losses (Margules and Pressey 2000, Crossman and Bryan 2006). In our study, increasing the restoration target from $25 \%$ to $30 \%$ of the landscape, means increasing land area from 968,316 to 1592 million hectares, which can represent a high socioeconomic cost in abandoning agricultural lands. However, because costs and resilience are not homogeneously distributed through the landscapes, by selecting areas of intermediate ecological resilience for the same restoration area target, the total area in SER scenario can be one third lower (354,277 ha) compared with the MLC scenario (Fig. 5). In our model, alternatively you can select only landscapes whose restoration cost is below the overall average (SRC scenario) and as a result expand the areas to be restored (from 354,277 on SER to 578,000 hectares on SRC scenario) while maintaining a global restoration cost $50 \%$ lower than the MLC scenario. In short, our framework allows us to visualize challenges that different decisions embrace, resulting in different costs and gains. Which is the best strategy? It depends. We would say that the best solution is focusing on the landscapes with intermediate resilience and low costs; however, the process of setting targets for restoration depends on human values, local demands, political situations, bureaucracy, and institutional arrangements (Rodrigues et al. 2009, Faleiro and Loyola 2013, Nilsson and Aradóttir 2013), which make it a context-dependent process.

In our model, for simplicity, we treated agricultural lands as a cost layer. Although this is a valid assumption because land uses represent the most important human foot-print on Earth, it also may mask important opportunities, including social and economic benefits (Venter et al. 2016). Nowadays, agricultural lands cover the highest percentage of the planet in the entire human history, and are expected to increase in coming years (Foley et al. 2011). This is particularly true for the Mato Grosso do Sul state where $\sim 60 \%$ of the vegetation of the Cerrado biome (surrounding Pantanal wetland) has been converted to other land uses and, if no effective control actions are taken, the natural vegetation from this region could be eliminated by 2050 (Silva et al. 2011, Roque et al. 2016). Our model shows a negative relationship between environmental resilience and agricultural production. It is not a surprising result considering that, although the current allocation of crops has many economic and social 
Fig. 6. (a) Three-dimensional plot relating the landscape resilience, restoration cost, and respective priorities index on the z-axis of 1423 planning units (PUs) with deficit to the habitat target of 30\%. The black outlines highlight the PUs whose values are less than 2271 restoration cost (average) but with resilience range greater than 0.08. (b) Map of priorities highlighting (yellow to orange colors) the 875 PUs from selection by restoration cost scenario, which were weighted by restoration cost and resilience. PUs into range of blue we predict the greatest conflicts to legal reserve restoration.

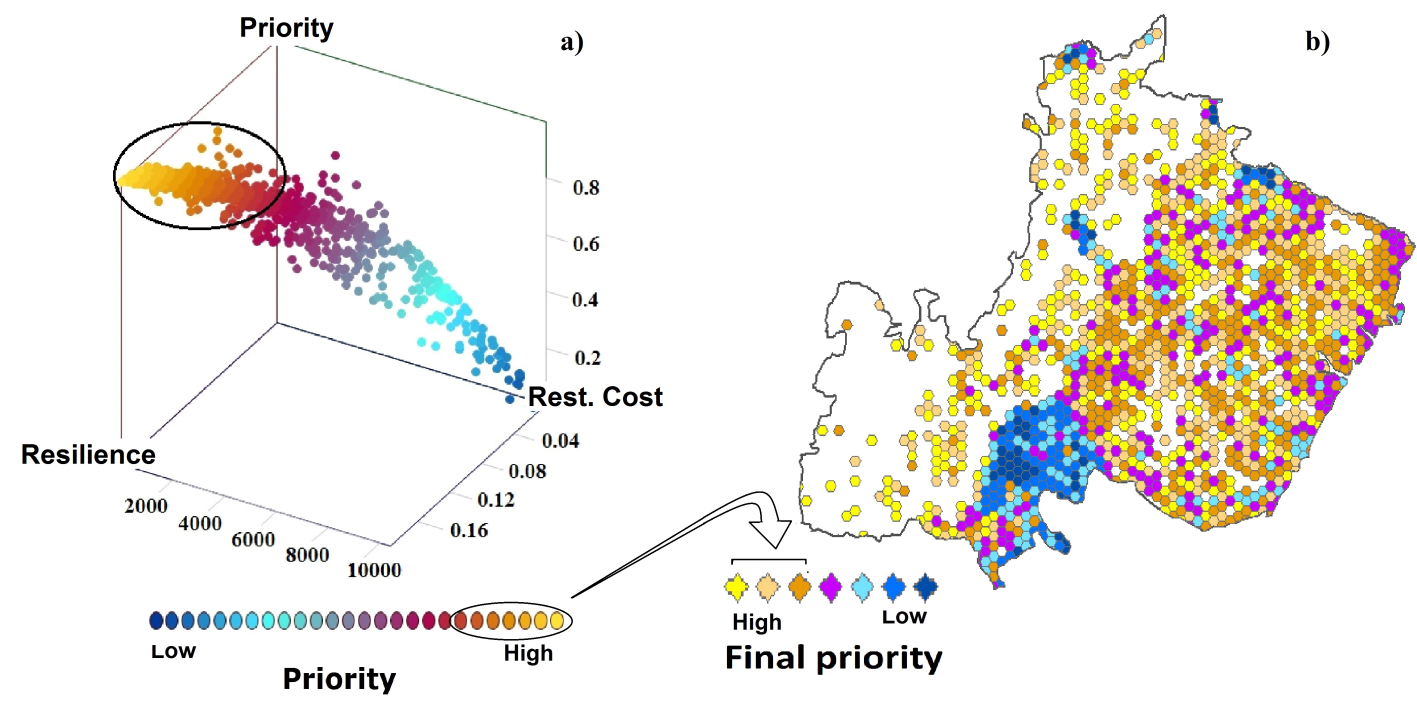

benefits, it also caused declines in biodiversity, carbon storage, and important environmental services (Foley et al. 2011, Laurance et al. 2014). Savannas will continue to lose environmental resilience on account of agricultural expansion in the coming years unless their impacts can be minimized by legal mechanisms, such as LR offsetting (see Soares-Filho et al. 2014). In Brazil, legal reserve offsetting has been part of the environmental tools since the year 2001 when the law 2.166-67/2001 modified the Forest Code enacted in 1965. The newest Forest Code (Government of Brazil 2012) enforces landowners to keep a certain percentage of natural vegetation on their land and stipulates that all landowners must register themselves in the rural environmental registry (Cadastro Ambiental Rural - CAR) and provide information on their land use in a geographic information system. It is expected that millions of dollars encompassing thousands of hectares will be negotiated in the future involving property compliances with the forest legislation. Despite the opportunities and some enthusiasm behind biodiversity offsetting, there are still many uncertainties in both the science behind the process and its implementation in the real world to guarantee no loss of biodiversity. To overcome part of these challenges, we suggest that offset planning should be based on achieving landscape-level compliance as we exemplified in our framework. Moreover, a recent analysis of economic and biophysical steady-state models to quantify the benefits of the Brazilian Forest Code (FC) under landscape and property-level planning in Brazilian savanna gives more support to the idea that landscape level mitigation provides cost-effective conservation and can be used to promote sustainable development (Kennedy et al. 2016).

Our results also reveal areas that can be particularly important for reconciling agriculture and landscape conservation/ restoration planning. These areas have high and intermediate resilience and also high or intermediate profitability. This could mean that increasing restoration in this area could be very expensive, assuming that our proxy roughly represents the restoration implementation cost. However, there is another important message here, that some areas can be simultaneously productive and maintain levels of resilience above the legal compliance. Concomitantly increasing crop productivity is not only a matter of expanding agricultural lands, but alternatively increasing agriculture efficiency without affecting landscape resilience. This idea can help to slow down agricultural expansion in tropical forests and savannas, shifting the current agricultural production pathway into a more sustainable one (Foley et al. 2011). In short, as Tambosi et al. (2014) demonstrated, landscapes with intermediate resilience represent an alternative path to find win-win scenarios. Areas of intermediate resilience and high productivity can promote greater sympathy and adhesion by stakeholders. Moreover, the intermediate ecological resilience enables adoption of more economical techniques for using nature resources of the remnants of the native landscapes near production areas. Furthermore, these areas can also be used to recreate cultural landscapes, and activate functional connectivity in order to optimize environmental services, such as pest control, pollination or water supply (Benayas et al. 2009), which facilitates win-win systems in human-dominated landscapes.

We have proposed a new framework to visualize restoration challenges at a landscape scale in the savanna region of Brazil, but much work remains to translate it into action. In terms of modeling and datasets, we made some assumptions that should be more critically evaluated in future works. By using total amount of habitat, its spatial configuration, and information about connectivity based on aggregated measure of animal dispersion 
(Sugai et al. 2014), we overcome the lack of fine information on resilience in savanna landscape; however more local data on biotic and abiotic restoration constraints, e.g., movement of the dispersers or soil condition, are needed to improve our model in terms of functional connectivity. Assessing cost is also a critical, although mistreated, step in spatial planning (Armsworth 2014). Our approach does not consider direct measures of economic costs such as acquisition, management, establishment, maintenance and transaction costs (Iftekhar et al. 2016), fines for noncompliance with the environmental law (Igari et al. 2009), costs in habitat restoration (Holl and Howarth 2000), or benefits from environmental services (e.g., Allsopp et al. 2008), thus future studies should consider how different socio-cultural and economical facets influence the outcomes accounting for other variables like infrastructure and accessibility. Despite its shortfalls, we believe that our framework should be part of the analytical toolbox for restoration planning, because it helps to visualize the challenges in a simple and transparent way. This is particularly useful in the first steps of building restoration strategies in regions marked by historical conflicts between land users and where information on biodiversity and restoration costs is limited.

Responses to this article can be read online at: http://www.ecologyandsociety.org/issues/responses. $\mathrm{php} / 8922$

\section{Acknowledgments:}

This study was supported by Programa de Pós-Graduação em Ecologia e Conservação PPEC/UFMS e FCBA/UFGD. We also thank Paulino Medina, Valguima Odakura, and Vito Comar for helpful comments on the early version of this manuscript. JMO received the post doctorate grant PNPD 1378381, CAPES. LSMS is grateful for grant \#2015/25316-6, São Paulo Research Foundation (FAPESP). FOR received a productivity grant from CNPq. The study was partially funded by the Fundect, Fundação Neotropica do Brasil and Zoneamento Ecológico Econômico de Mato Grosso do Sul.

\section{LITERATURE CITED}

Allsopp, M. H., W. J. De Lange, and R. Veldtman. 2008. Valuing insect pollination services with cost of replacement. PLOS ONE 3(9):e3128. http://dx.doi.org/10.1371/journal.pone.0003128

Armsworth, P. R. 2014. Inclusion of costs in conservation planning depends on limited datasets and hopeful assumptions. Annals of the New York Academy of Sciences 1322(1):61-76. http:// dx.doi.org/10.1111/nyas.12455

Aronson, J., C. Floret, E. Floc'h, C. Ovalle, and R. Pontanier. 1993. Restoration and rehabilitation of degraded ecosystems in arid and semi-arid lands. I. A view from the south. Restoration Ecology 1(1):8-17. http://dx.doi.org/10.1111/j.1526-100X.1993. $\underline{\text { tb00004.x }}$

Banks-Leite, C., R. M. Ewers, V. Kapos, A. C. Martensen, and J. P. Metzger. 2011. Comparing species and measures of landscape structure as indicators of conservation importance. Journal of
Applied Ecology 48(3):706-714. http://dx.doi.org/10.1111/ j.1365-2664.2011.01966.X

Banks-Leite, C., R. Pardini, L. R. Tambosi, W. D. Pearse, A. A. Bueno, R. T. Bruscagin, T. H. Condez, M. Dixo, A. T. Igari, A. C. Martensen, and J. P. Metzger. 2014. Using ecological thresholds to evaluate the costs and benefits of set-asides in a biodiversity hotspot. Science 345(6200):1041-1045. http://dx.doi.org/10.1126/ science. 1255768

Benayas, J. M. R., A. C. Newton, A. Diaz, and J. M. Bullock. 2009. Enhancement of biodiversity and ecosystem services by ecological restoration: a meta-analysis. Science 325(5944):1121-1124. http://dx.doi.org/10.1126/science. 1172460

Brancalion, P. H. S., L. C. Garcia, R. Loyola, R. R. Rodrigues, V. D. Pillar, and T. M. Lewinsohn. 2016. A critical analysis of the Native Vegetation Protection Law of Brazil (2012): updates and ongoing initiatives. Natureza \& Conservação 14(S1):1-15. http:// dx.doi.org/10.1016/j.ncon.2016.03.003

Brancalion, P. H., R. A. G. Viani, B. B. N. Strassburg, and R. R. Rodrigues. 2012. Finding the money for tropical forest restoration. Unasylva 631:239.

Buchanan, J. M. 1991. Opportunity cost. Pages 520-525 in J. Eatwell, M. Milgate, and P. Newman, editors. The world of economics. Palgrave Macmillan, Basingstoke, UK. http://dx.doi. org/10.1007/978-1-349-21315-3 69

Crossman, N. D., and B. A. Bryan. 2006. Systematic landscape restoration using integer programming. Biological Conservation 128(3):369-383. http://dx.doi.org/10.1016/j.biocon.2005.10.004

Crouzeilles, R., H. L. Beyer, M. Mills, C. E. Grelle, and H. P. Possingham. 2015. Incorporating habitat availability into systematic planning for restoration: a species-specific approach for Atlantic Forest mammals. Diversity and Distributions 21 (9):1027-1037. http://dx.doi.org/10.1111/ddi.12349

Faleiro, F. V., and R. D. Loyola. 2013. Socioeconomic and political trade-offs in biodiversity conservation: a case study of the Cerrado Biodiversity Hotspot, Brazil. Diversity and Distributions 19(8):977-987. http://dx.doi.org/10.1111/ddi.12072

Foley, J. A., N. Ramankutty, K. A. Brauman, E. S. Cassidy, J. S. Gerber, M. Johnston, N. D. Mueller, C. O'Connell, D. K. Ray, P. C. West, et al. 2011. Solutions for a cultivated planet. Nature 478:337-342. http://dx.doi.org/10.1038/nature10452

Government of Brazil. 1981. National Environmental Policy. Law $n^{\circ}$ 6.938, August 1981. Government of Brazil, Brasilia, Brazil. [online] URL: http://www.mma.gov.br/port/conama/legiabre. cfm?codlegi $=313$

Government of Brazil. 2012. Forest code. Law $n^{\circ}$ 12.651, May 2012. Government of Brazil, Brasilia, Brazil. [online] URL: http://www.planalto.gov.br/ccivil 03/ Ato2011-2014/2012/Lei/L12651. $\underline{\mathrm{htm}}$

Hall, C. M. 1988. The "worthless lands hypothesis" and Australia's national parks and reserves. Pages 441-459 in K. J. Frawley and N. Semple, editors. Australia's ever changing forests. Australian Defence Force Academy, Canberra, Australia.

Holl, K. D., and R. B. Howarth. 2000. Paying for restoration. Restoration Ecology 8(3):260-267. http://dx.doi.org/10.1046/ j.1526-100x.2000.80037.x 
Iftekhar, M. S., M. Polyakov, D. Ansell, F. Gibson, and G. Kay. 2016. How economics can further the success of ecological restoration. Conservation Biology. http://dx.doi.org/10.1111/ cobi. 12778

Igari, A. T., L. R. Tambosi, and V. R. Pivello. 2009. Agribusiness opportunity costs and environmental legal protection: investigating trade-off on hotspot preservation in the State of São Paulo, Brazil. Environmental Management 44(2):346-355. http:// dx.doi.org/10.1007/s00267-009-9322-8

IMASUL (Mato Grosso do Sul Institute of Environment). 2015. Map land use 2010. Database. IMASUL, Campo Grande, Brazil. [online] URL: http://sisla.imasul.ms.gov.br/sisla/pagina inicial. php

INPE/Canasat (Brazilian National Institute for Space Research). 2015. Sugarcane crop monitoring in Brazil. INPE, São José, Brazil. [online] URL: http://www.dsr.inpe.br/laf/canasat/en/

Jackson, S. T., and R. J. Hobbs. 2009. Ecological restoration in the light of ecological history. Science 325(5940):567-569. http:// dx.doi.org/10.1126/science.1172977

Joppa, L. N., B. O’Connor, P. Visconti, C. Smith, J. Geldmann, M. Hoffmann, J. E. M. Watson, S. H. M. Butchart, M. VirahSawmy, B. S. Halpern, S. E. Ahmed, A. Balmford, W. J. Sutherland, M. Harfoot, C. Hilton-Taylor, W. Foden, E. Di Minin, S. Pagad, P. Genovesi, J. Hutton, N. D. Burgess. 2016. Filling in biodiversity threat gaps. Science 352(6284):416-418. http://dx.doi.org/10.1126/science.aaf3565

Kennedy, C. M., D. A. Miteva, L. Baumgarten, P. L. Hawthorne, K. Sochi, S. Polasky, J. R. Oakleaf, E. M. Uhlhorn, and J. Kiesecker. 2016. Bigger is better: improved nature conservation and economic returns from landscape-level mitigation. Science Advances 2(7):e1501021. http://dx.doi.org/10.1126/sciadv.1501021

Lamb, D., P. D. Erskine, and J. A. Parrotta. 2005. Restoration of degraded tropical forest landscapes. Science 310(5754):1628-1632. http://dx.doi.org/10.1126/science.1111773

Laurance, W. F., J. Sayer, and K. G. Cassman. 2014. Agricultural expansion and its impacts on tropical nature. Trends in Ecology \& Evolution 29(2):107-116. http://dx.doi.org/10.1016/j.tree.2013.12.001

Lourival, R., H. McCallum, G. Grigg, C. Arcangelo, R. Machado, and H. Possingham, 2009. A systematic evaluation of the conservation plans for the Pantanal wetland in Brazil. Wetlands 29(4):1189-1201. http://dx.doi.org/10.1672/08-118.1

Loyola, R. D., L. G. R. Oliveira-Santos, M. Almeida-Neto, D. M. Nogueira, U. Kubota, J. A. F. Diniz-Filho, and T. M. Lewinsohn. 2009. Integrating economic costs and biological traits into global conservation priorities for carnivores. PLOS ONE 4 (8):e6807. http://dx.doi.org/10.1371/journal.pone.0006807

Margules, C. R., and R. L. Pressey. 2000. Systematic conservation planning. Nature 405:243-253. http://dx.doi.org/10.1038/35012251

Metzger, J. P., and P. H. S. Brancalion. 2013. Challenges and opportunities in applying a landscape ecology perspective in ecological restoration: a powerful approach to shape neolandscapes. Brazilian Journal of Nature Conservation 12 (2):103-107. http://dx.doi.org/10.4322/natcon.2013.018
Minnemeyer, S., L. Laestadius, N. Sizer, C. Saint-Laurent, and P. Potapov. 2011. A world of opportunity. World Resources Institute, Washington, D.C., USA. [online] URL: http://www.wri.org/sites/ default/files/world_of_opportunity_brochure_2011-09.pdf

Moffett, A., and S. Sarkar. 2006. Incorporating multiple criteria into the design of conservation area networks: a mini review with recommendations. Diversity and Distributions 12(2):125-137. http://dx.doi.org/10.1111/j.1366-9516.2005.00202.x

Myers, N., R. A. Mittermeier, C. G. Mittermeier, G. A. da Fonseca, and J. Kent. 2000. Biodiversity hotspots for conservation priorities. Nature 403:853-858. http://dx.doi.org/10.1038/35002501

Nilsson, C., and Á. L. Aradóttir. 2013. Ecological and social aspects of ecological restoration: new challenges and opportunities for northern regions. Ecology and Society 18(4):35. http://dx.doi.org/10.5751/ES-06045-180435

Noss, R., S. Nielsen, and K. Vance-Borland. 2009. Prioritizing ecosystems, species, and sites for restoration. Pages 158-171 in A. Moilanen, K. A. Wilson, and H. P. Possingham, editors. Spatial conservation prioritization: quantitative methods and computational tools. Oxford University Press, Oxford, UK.

Ochoa-Quintero, J. M., T. A. Gardner, I. Rosa, S. F. Barros Ferraz, and W. J. Sutherland. 2015. Thresholds of species loss in Amazonian deforestation frontier landscapes. Conservation Biology 29(2):440-451. http://dx.doi.org/10.1111/cobi.12446

Overbeck, G. E., E. Vélez-Martin, F. R. Scarano, T. M. Lewinsohn, C. R. Fonseca, S. T. Meyer, S. C. Müller, P. Ceotto, L. Dadalt, G. Durigan, G. Ganade, M. M Gossner, D. L. Guadagnin, K. Lorenzen, C. M. Jacobi, W. W. Weisser, and V. D. Pillar. 2015. Conservation in Brazil needs to include non-forest ecosystems. Diversity and Distributions 21(12):1455-1460. http:// dx.doi.org/10.1111/ddi.12380

Pardini, R., A. D. A. Bueno, T. A. Gardner, P. I. Prado, and J. P. Metzger. 2010. Beyond the fragmentation threshold hypothesis: regime shifts in biodiversity across fragmented landscapes. $P L O S$ ONE 5(10):e13666. http://dx.doi.org/10.1371/journal.pone.0013666

Pascual-Hortal, L., and S. Saura. 2006. Comparison and development of new graph-based landscape connectivity indices: towards the priorization of habitat patches and corridors for conservation. Landscape Ecology 21(7):959-967. http://dx.doi. org/10.1007/s10980-006-0013-Z

Phalan, B., M. Onial, A. Balmford, and R. E. Green. 2011. Reconciling food production and biodiversity conservation: land sharing and land sparing compared. Science 333(6047):1289-1291. http://dx.doi.org/10.1126/science.1208742

Rodrigues, M. E., F. O. Roque, J. M. Ochoa-Quintero, J. C. de Castro Pena, D. C. de Sousa, and P. D. M. Junior. 2016. Nonlinear responses in damselfly community along a gradient of habitat loss in a savanna landscape. Biological Conservation 194:113-120. http://dx.doi.org/10.1016/j.biocon.2015.12.001

Rodrigues, R. R., R. A. F. Lima, S. Gandolfi, and A. G. Nave. 2009. On the restoration of high diversity forests: 30 years of experience in the Brazilian Atlantic Forest. Biological Conservation 142(6):1242-1251. http://dx.doi.org/10.1016/j. biocon.2008.12.008 
Roque, F. O., J. M. Ochoa-Quintero, D. B. Ribeiro, L. S. M. Sugai, R. Costa-Pereira, R. Lourival, and G. Bino. 2016. Upland habitat loss as a threat to Pantanal wetlands. Conservation Biology 30 (5):1131-1134. http://dx.doi.org/10.1111/cobi.12713

Silva, J. S.V., M. M. Abdon, S. M. A. da Silva, and J. A. Moraes. 2011. Evolution of deforestation in the Brazilian Pantanal and surroundings in the timeframe 1976-2008. Geografia 36:35-55.

Soares-Filho, B., R. Rajão, M. Macedo, A. Carneiro, W. Costa, M. Coe, H. Rodrigues, and A. Alencar. 2014. Cracking Brazil's forest code. Science 344(6182):363-364. http://dx.doi.org/10.1126/ science. 1246663

Steffen, W., K. Richardson, J. Rockström, S. E. Cornell, I. Fetzer, E. M. Bennett, R. Biggs, S. R. Carpenter, W. Vries, C. A. Wit, C. Folke, D. Gerten, J. Heinke, G. M. Mace, L. M. Persson, V. Ramanathan, B. Reyers, and S. Sörlin. 2015. Planetary boundaries: guiding human development on a changing planet. Science 347(6223). http://dx.doi.org/10.1126/science.1259855

Sugai, L. S. M., R. Costa-Pereira, J. M. Ochoa-Quintero, S. Torrecilha, A. Eriksson, A. P. Nunes, and P. Medici 2014. Incorporating biodiversity expert knowledge in landscape conservation planning: a case study involving the Pantanal. Anais 5th Simpósio de Geotecnologias no Pantanal. Embrapa Informática Agropecuária/INPE, São José, Brazil.

Sullivan, L. 2013. Identity, territory and land conflict in Brazil. Development and Change 44:451-471. http://dx.doi.org/10.1111/ dech. 12010

Tambosi, L. R., A. C. Martensen, M. C. Ribeiro, and J. P. Metzger. 2014. A framework to optimize biodiversity restoration efforts based on habitat amount and landscape connectivity. Restoration Ecology 22(2):169-177. http://dx.doi.org/10.1111/rec.12049

Venter, O., E. W. Sanderson, A. Magrach, J. R. Allan, J. Beher, K. R. Jones, H. P. Possingham, W. F. Laurance, P. Wood, B. M. Fekete, M. A. Levy, and J. E. M. Watson. 2016. Sixteen years of change in the global terrestrial human footprint and implications for biodiversity conservation. Nature Communications 7:12558. http://dx.doi.org/10.1038/ncomms12558 